\title{
ANÁLISE DA EXPANSÃO CANAVIEIRA E AS MUDANÇAS DE USO DO SOLO NO SUDOESTE GOIANO DE 1985 A 2016
}

\author{
ANALYSIS OF SUGARCANE EXPANSION AND SOIL USE CHANGES IN \\ THE SOUTHWEST OF GOIÁS IN THE YEARS FROM 1985 TO 2016
}

\author{
ANALYSE DE L'EXPANSION DE LA CANNE À SUCRE ET \\ DU CHANGEMENT DE L'UTILIZATION DES SOLS DANS LE \\ SUD-OUEST DE L' ÉTAT D GOIÁS DE 1985 À 2016
}
Silas Pereira Trindade - Universidade Estadual de Goiás - Goiás - Pires do Rio - Brasil
silaspereiratrindade@gmail.com

Karla Faria - Universidade Federal de Goiás - Goiás - Goiânia - Brasil

karlamsfaria@gmail.com
Selma Simões de Castro - Universidade Federal de Goiás - Goiás - Goiânia - Brasil selma.castro@uol.com.br

\section{Resumo}

A Região de Planejamento do Sudoeste Goiano (RPSG) se insere na área da recente e rápida expansão sucroenergética brasileira no Centro-Sul do Cerrado a partir dos anos 2000. 0 avanço do setor criou um ambiente de competição pelas melhores áreas produtivas entre os complexos agroindustriais instalados na região, principalmente 0 de grãos e 0 de carne. As maiores evidências disso se encontram nas mudanças de uso do solo, em que a cana-de-açúcar vem substituindo, de forma direta e indireta, áreas de agricultura, pastagens e também de Cerrado remanescente. Com uso de geotecnologias analisou-se a influência dessa expansão canavieira na dinâmica espacial da RPSG, nos anos de 1985, 1995, 2005, 2010, 2013 e 2016, que cobrem o período anterior, concomitante e posterior à essa expansão, considerando os padrões de sucessão de usos. Os resultados mostraram que a cana-de-açúcar avançou sobre as áreas agrícolas e pecuárias, mas também sobre as naturais, em busca dos melhores solos, o que está relacionado à maior rentabilidade da cultura, interferindo na produção de alimentos e nas áreas de vegetação nativa.

Palavras-chave: Setor sucroenergético, mudanças de uso do solo, conflitos de uso do solo.

\begin{abstract}
The Southwest Planning Region of Goiás (RPSG) is part of the recent and rapid Brazilian sugarcane expansion in the Center-South of the Brazilian Savannah named Cerrado, from 1985 to 2016. So this article emphasizes the periods before, during and after the expansion. The sector's growing created an environment of competition for the best productive areas between agroindustrial complexes in the region, mainly grains and meat. The main evidence of that is found in changes in land use, as sugar cane has been directly and indirectly replacing agricultural, pasture and Cerrado remnant. The influence of this sugarcane expansion on the spatial dynamics of RPSG in 1985, 1995, 2005, 2010, 2013 and 2016, is analyzed considering the previous, concomitant and subsequent period of this expansion. To do so, geotechnologies were applied to analyze the succession and conflicts of uses. The results showed that sugarcane advanced upon the agricultural and livestock areas, but also on the natural ones, in search of the best soils, which is related to the greater profitability of the crop, interfering in the production of food and in the areas of native vegetation.

Keywords: Sugar-energy sector; changes in land use; conflicts of land use.
\end{abstract}




\section{Résumé}

La région de planification du sud-ouest de l'état de Goiás (RPSG) fait partie de la region de l'expansion récente et rapide de la canne à sucre brésilienne au centre-sud du Cerrado, des années 1985 jusqu' à 2016, avant, pendant et après I' expansion. L'avancée du secteur a créé un climat de concurrence pour les meilleures zones de production entre complexes agro-industriels dans la région, principalement occupés para des céréales et de la viande, dont les principales évidences sont les changements d'utilisation des terres, où la canne à sucre a remplacé directement et indirectement les cultures agricoles, les pâturages et des fragments du Cerrado. L'influence de cette expansion sur la dynamique spatiale du RPSG en 1985, 1995, 2005, 2010, 2013 et 2016, couvrant la période précédente, concomitante et ultérieure à cette expansion, a été analysée à l'aide de geotechnologies, en faisant ressortir ceux que la canne à sucre a remplacé et la succession d'utilisations dans le temps. Les résultats ont montré que la canne à sucre a progressée sur les zones agricoles et d'élevage, mais aussi sur les zones naturelles, en recherchant toujours des meilleurs sols, ce qui est lié à la plus grande rentabilité de la culture, où s'ingéré dans la production alimentaire et les zones de végétation. natif.

Mots-clés: bioénergie; changements de l'utilisation des terres; conflits d'utilisation des terres.

\section{Introdução}

A crise ambiental mundial e as projeções futuras de escassez do petróleo incentivaram a busca por fontes alternativas de energia com base em matrizes renováveis com menores níveis de emissões de Gases do Efeito Estufa (GEE). Neste contexto, a biomassa da cana-de-açúcar, por meio da indústria sucroenergética, insere o Brasil, em especial as áreas de Cerrado, no contexto internacional, como um dos grandes produtores desta nova matriz energética, o etanol da cana-de-açúcar (Macedo, 2005; Sauer; Pietrafesa, 2012).

A produção sucroenergética como substituto do petróleo no Brasil ocorreu em dois períodos distintos: nas décadas de 1970 e de 2000 . O primeiro deles vinculou-se ao processo de modernização da agricultura, fortemente subsidiado pelo governo federal, e foi intitulado Programa Nacional do Álcool-PROÁLCOOL, tendo iniciado na década de 1970 e encerrado no início da década de 1990. O PROÁLCOOL resultou numa notável concentração de áreas plantadas e de usinas no Sudeste do país, sobretudo no estado de São Paulo. O segundo período, correspondente à recente expansão, iniciou-se nos anos 2000, vinculado ao Plano Nacional de Agroenergia - PNA (Castro et al., 2010) e amparado pelo Zoneamento Agroecológico da Cana-de-Açúcar-ZAE/Cana (Manzatto et al., 2009).

Ambos buscaram inserir o agronegócio brasileiro num lugar de destaque internacional no setor de produção de energias renováveis. Além disso, propuseram o desenvolvimento sustentável criando diretrizes de integração social e de ordenamento do avanço canavieiro para as áreas 
antropizadas, apoiadas por ações legais e financeiras, federais e estaduais, que descentralizaram a produção, até então concentrada na região Nordeste do País, para o centro-sul do bioma Cerrado (Castro et al, 2010: Sauer; Pietrafesa, 2012).

O Cerrado, nos últimos 40 anos, perdeu grande parte da sua área para as monoculturas comerciais e também para as pastagens. A cana-deaçúcar vem avançando sobre essas áreas, promovendo a substituição dos usos praticados e seu subsequente deslocamento: dos grãos para as áreas de pastagens, com maior exigência de práticas conservacionistas, e das pastagens para as áreas de remanescentes de vegetação nativa (Abdala; Castro, 2010; Castro et al, 2010; Barbalho et al, 2013). Tal expansão vem promovendo ganhos econômicos regionais, mas também efeitos negativos nos ambientes, como a perda da qualidade do solo e da água, problemas de saúde humana e riscos para a biodiversidade (Houtart, 2010; Silva, A. et al., 2011; Silva, A.; Castro, 2015).

O estado de Goiás configura-se num dos estados com uma das maiores expansões canavieiras no Brasil. A ocupação dos solos goianos, pela cana-de-açúcar, ocorre diante do contexto de uma concentração regional, desencadeadora de um modelo competitivo entre culturas, principalmente pela sojicultura, no bojo da expansão da fronteira agrícola. Esse avanço do setor ocorre sob a dependência do mercado internacional do etanol, criando um elevado uso de capital técnico, por meio de máquinas, insumos e financiamentos (Lima; Garcia, 2011). Além do intenso envolvimento de recursos tecnológicos na produção, também se buscam os melhores recursos naturais, atingindo as áreas de solos de melhor aptidão agrícola, antes ocupados com grãos, em particular soja, ampliando as possibilidades de aumento e ganho de produtividade (Prado; Miziara; Ferreira, M. F., 2012; Barbalho; Silva, A.; Castro, 2013).

Para isso, a Região de Planejamento do Sudoeste Goiano (RPSG), ou simplesmente o Sudoeste Goiano, adotou o modelo de desenvolvimento de produção agrícola intensificado por meio de políticas públicas de modernização, induzidas principalmente pelo Programa de Desenvolvimento do Cerrado (POLOCENTRO) e pelo Programa de Cooperação Nipo-Brasileira para o Desenvolvimento do Cerrado (PRODECER), que implementaram o modelo técnico-econômico trazido pela Revolução Verde na década de 1970 no País. Esse processo resultou na estruturação de complexos agroindustriais caracterizados pelo intenso 
uso das terras, destacando-se regionalmente os complexos de grãos, carne e o próprio setor sucroenergético.

A recente expansão canavieira na RPSG desenvolveu a dinâmica de competição pelo uso do solo entre os complexos agroindustriais instalados na região, processo descrito na literatura pelo avanço da cana-de-açúcar sobre as áreas agrícolas e o seu deslocamento, bem como sobre as áreas de estoques de terras, principalmente as inaproveitáveis, além de sobre remanescentes florestais, que também sofrem deslocamento das culturas anuais e das pastagens anteriores à chegada da cana, para áreas vizinhas (Abdala; Ribeiro, 2011).

Dessa maneira, o avanço da cana-de-açúcar na RPSG materializa o processo de mudanças de uso do solo, as quais entram em conflito com as outras atividades agropecuárias da região, e são influenciadas pelo contexto físico e também socioeconômico. Para Santos (2004), a interpretação de polígonos de usos, numa sucessão histórica, retrata a relação das atividades antrópicas e o meio natural, demonstrando os impactos e as pressões sobre os sistemas naturais (Sauer; Pietrafesa, 2012).

Diante disso, o objetivo deste estudo foi analisar a expansão do setor sucroenergético no Sudoeste Goiano, por meio da dinâmica do uso do solo, avaliando a influência das mudanças de usos, em relação à substituição direta pela cana-de-açúcar e indireta desta para culturas e pastagens, com base nos anos de 1985 e 1995, anteriores à expansão recente, e de 2005, 2010, 2013 e 2016, referentes ao período da expansão contemporânea e relativa estabilização.

\section{Material e métodos}

\section{Área de estudo}

A RPSG situa-se em área do bioma Cerrado e localiza-se na porção Sudoeste do Estado de Goiás, ocupando $\sim 18 \%$ do estado, equivalendo a $61.500 \mathrm{~km}^{2}$. A região é composta por 26 municípios e se destaca como uma das mais importantes áreas de produção agrícola do Brasil, devido às suas características edafoclimáticas e geomorfológicas, que agregam grande potencial para a agricultura motomecanizada, dita moderna (Figura 1). 
Localização das Usinas Sucroalcooleiras no Sudoeste Goiano-2017
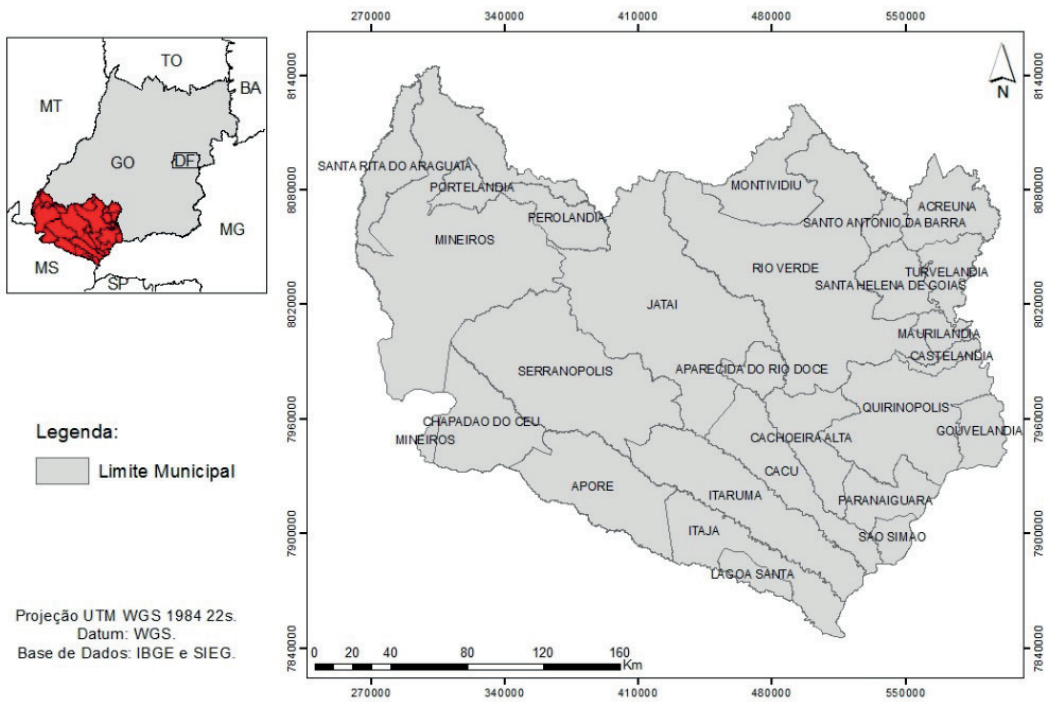

Figura 1-Mapa de localização da área de estudo e das usinas sucroenergéticas.

Fonte: Bases de dados da Sindicato da Indústria de Fabricação de Etanol do Estado de Goiás e do Sistema Estadual de Geoinformação de Goiás.

Nos últimos anos, a RPSG passou por um intenso crescimento sucroenergético, fato verificado pelo aumento no número de usinas processadoras de etanol e açúcar e de áreas plantadas com a cultura da cana-de-açúcar. O crescimento foi marcado pelo aumento do número de usinas, distribuído em três importantes períodos correspondentes aos anos de 1946 a 1986, com três usinas; de 2003 a 2009, com mais oito usinas; e 2012 a 2017, com mais cinco usinas, totalizando-se 16 unidades produtivas que foram influenciadas pelo PROÁLCOOL até o final da década de 1990, passando pela implantação do Plano Nacional de Agroenergia e a sua consolidação desde os anos 2000 (Figura 2). 
Distribuição das Usinas Sucroalcooleira no Sudoeste Goiano-1946-2017

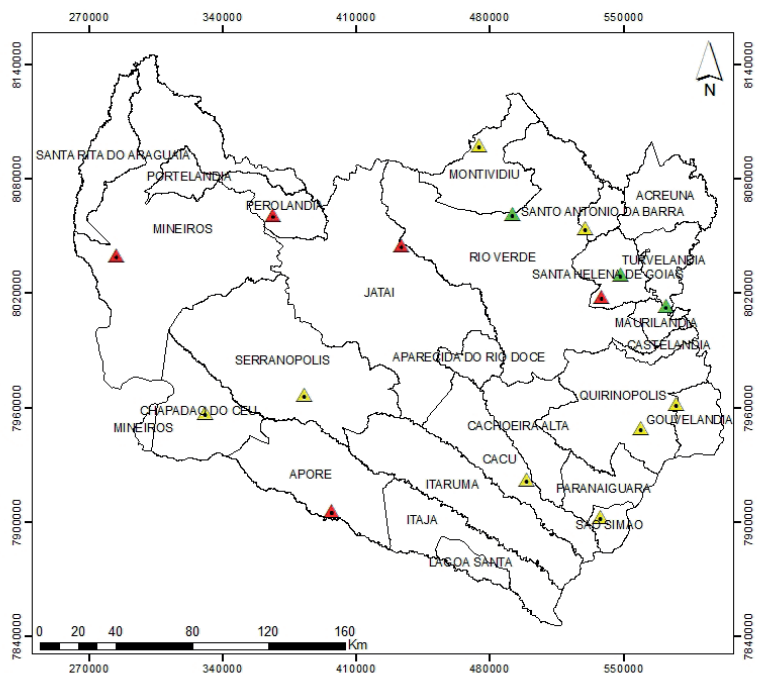

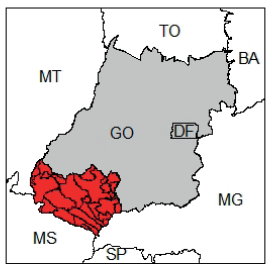

Legenda: Implantação

$\triangle \quad 1946-1999$

$\triangle \quad 2000-2009$

A $\quad 2010-2017$

Projeção UTM WGS 1984 22s Datum: WGS Base de Dados: SIFAEG, IBGE e SIEG

Figura 2-Avanço das usinas sucroalcooleiras na Região de Planejamento do Sudoeste Goiano.

Fonte: Bases de dados da Sindicato da Indústria de Fabricação de Etanol do Estado de Goiás e do Sistema Estadual de Geoinformação de Goiás.

Em sua base física, o Sudoeste Goiano encontra-se em áreas de bacias sedimentares dos Rios Araguaia e Paranaíba, com predomínio litológico de basaltos e arenitos e solos derivados (Latrubesse; Carvalho, 2006). Nelas prevalecem o domínio de relevo planáltico tabuliforme (Chapadas e Chapadões), com baixa declividade, associado aos Latossolos Vermelhos e Latossolos Vermelho-Amarelos, de potencial agrícola médio a alto (Manzatto et al., 2009; Castro et al., 2010).

\section{Sensoriamento remoto e a cana-de-açúcar}

O Sensoriamento Remoto é uma importante ferramenta para o monitoramento agrícola. Ele possibilita realizar análises sucessivas temporais de grandes áreas, com custos reduzidos e de forma remota, diante de uma relação integrada com outros sistemas naturais. Assim, a utilização de imagens de satélites para o monitoramento da cultura 
canavieira se insere nessas relações porque esta é uma cultura de ciclo longo, por isso para alguns semi-perene, que ocupa grandes extensões de terras (Oliveira, E.; Ferreira, M. E.; Araújo, 2012). As aplicações dessa técnica para o mapeamento da cana-de-açúcar resultam em análises precisas para o monitoramento da sua expansão e dos usos que substituiu (Rudorff; Sugawara, 2007).

Com isso, o desenvolvimento desta pesquisa teve como base o mapeamento multitemporal do uso do solo da RPSG, com o objetivo de caracterizar a dinâmica das mudanças de uso do solo promovidas pela expansão da cana-de-açúcar.

O roteiro metodológico adotado está ilustrado no fluxograma da Figura 3.

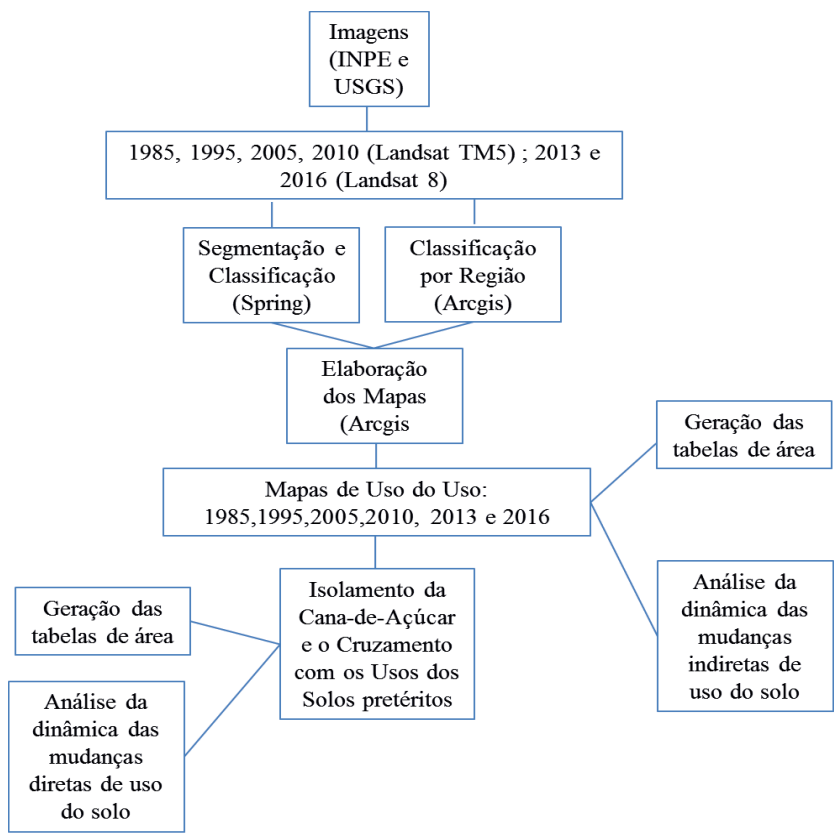

Figura 3 - Fluxograma das etapas para elaboração dos mapas de uso do solo e as mudanças de usos. 
Aquisição das imagens de satélite

As imagens de satélites utilizadas nesta pesquisa formaram o banco de dados multitemporal para a análise da dinâmica da canade-açúcar na RPSG. Utilizaram-se imagens Landsat TM5 e Landsat 8 obtidas no Instituto Nacional de Pesquisas Espaciais (INPE) e no Unident State Geological Survey (USGLS), com resolução espacial de 30 metros, correspondentes aos anos de 1985, 1995, 2005, 2010, 2013 e 2016. Para amenizar as interferências atmosféricas, adotou-se o período de inverno, preferencialmente julho, para assegurar a ausência de nuvens.

Foram realizadas as composições coloridas das imagens na falsa cor RGB, composição 345, para o Landsat TM5; e a composição 654, para o Landsat 8. A escolha dessas composições baseou-se na resposta espectral da cana-de-açúcar, que se apresentou visível e mapeável nessas bandas. Após, as imagens passaram pela correção geométrica (georreferenciamento) e foram delimitadas geograficamente levando em consideração cada município da região de estudo.

Segmentação, classificação e elaboração dos Mapas de Uso do Solo

As imagens de satélite passaram pelo processo de segmentação não-supervisionada, que consiste na rotulação dos pixels, reunindo as características homogêneas de grupos de informações digitais (Coutinho, 1997). Para realizar essa etapa, utilizou-se o classificador de Bhattacharya, disponível no programa Spring, com o agrupamento de 55 classes temáticas, que foram classificadas no programa Arcgis, levando em consideração o comportamento espectral dos alvos.

Os mapeamentos do uso do solo, juntamente com o layout final, também foram desenvolvidos no Arcgis, por meio da adaptação das classes do Manual de Uso da Terra (IBGE, 2006), considerando as culturas anuais, pastagem, vegetação, cana-de-açúcar, água e área urbana, na escala de 1:100.000. Após a construção dos mapas multitemporais dos anos selecionados, gerou-se o quadro de áreas em hectares das classes de uso adotadas por meio do mesmo software, com a ferramenta Xtools. 
Interpolação dos polígonos de cana com os usos pretéritos

Os polígonos das áreas de cana-de-açúcar foram isolados e cruzados com os mapas de uso do solo dos anos anteriores, com uso da ferramenta Intersect do Arcgis. Esse procedimento possibilitou analisar quais eram as classes de usos anteriores ao avanço da cana-de-açúcar, gerando a sucessão de uso do que a cana substituiu diretamente, dentro de um raio de $40 \mathrm{~km}$ das usinas, gerado por meio da ferramenta buffer. Nessas áreas foi criada a relação da substituição pela cana por pares de anos: 1985/1995, 1995/2005, 2005/2010, 2010/2013 e 2013/2016 de modo a refinar a análise. A análise de uso indireta ocorreu por meio da variação das classes de usos totais da RPSG. Por fim, também com a ferramenta Xtools do Arcgis, gerou-se o quadro de áreas em hectares das classes que a cana-de-açúcar substituiu.

A dinâmica multitemporal do uso do solo considera a evolução das atividades antrópicas sobre os recursos naturais, permitindo a integração da análise do meio físico com os aspectos sociais e econômicos (Oliveira, W., Ferreira, N., 2015). Dessa forma, foi possível analisar a expansão da cana-de-açúcar em relação às múltiplas coberturas identificadas neste estudo.

\section{Resultados e discussão}

\section{A expansão canavieira no Sudoeste Goiano}

Com a classificação das imagens multiespectrais dos satélites Landsat TM5 e Landsat 8, foi possível mapear seis classes de uso presentes na região: agricultura, drenagem, área urbana, cana-de-açúcar, pastagem e vegetação, considerando o critério temporal e possibilitando a compreensão da distribuição espacial da RPSG na escala de 1:100.000 (Figura 4).

A dinâmica do uso do solo no Sudoeste Goiano apresentou o predomínio de quatro classes de usos, sendo: a agricultura, a vegetação, a pastagem e a cana-de-açúcar. A partir do ano de 1985 até o ano de 2016, a agricultura e a pecuária apresentaram oscilações quanto às suas áreas de produção, registrando avanços intercalados de sucessivos retrocessos. A cana-de-açúcar foi a classe de uso que atingiu um constante crescimento em todo o período analisado, ao contrário da vegetação nativa, que apresentou uma constante queda, conforme pode ser visualizado na Tabela 1. 


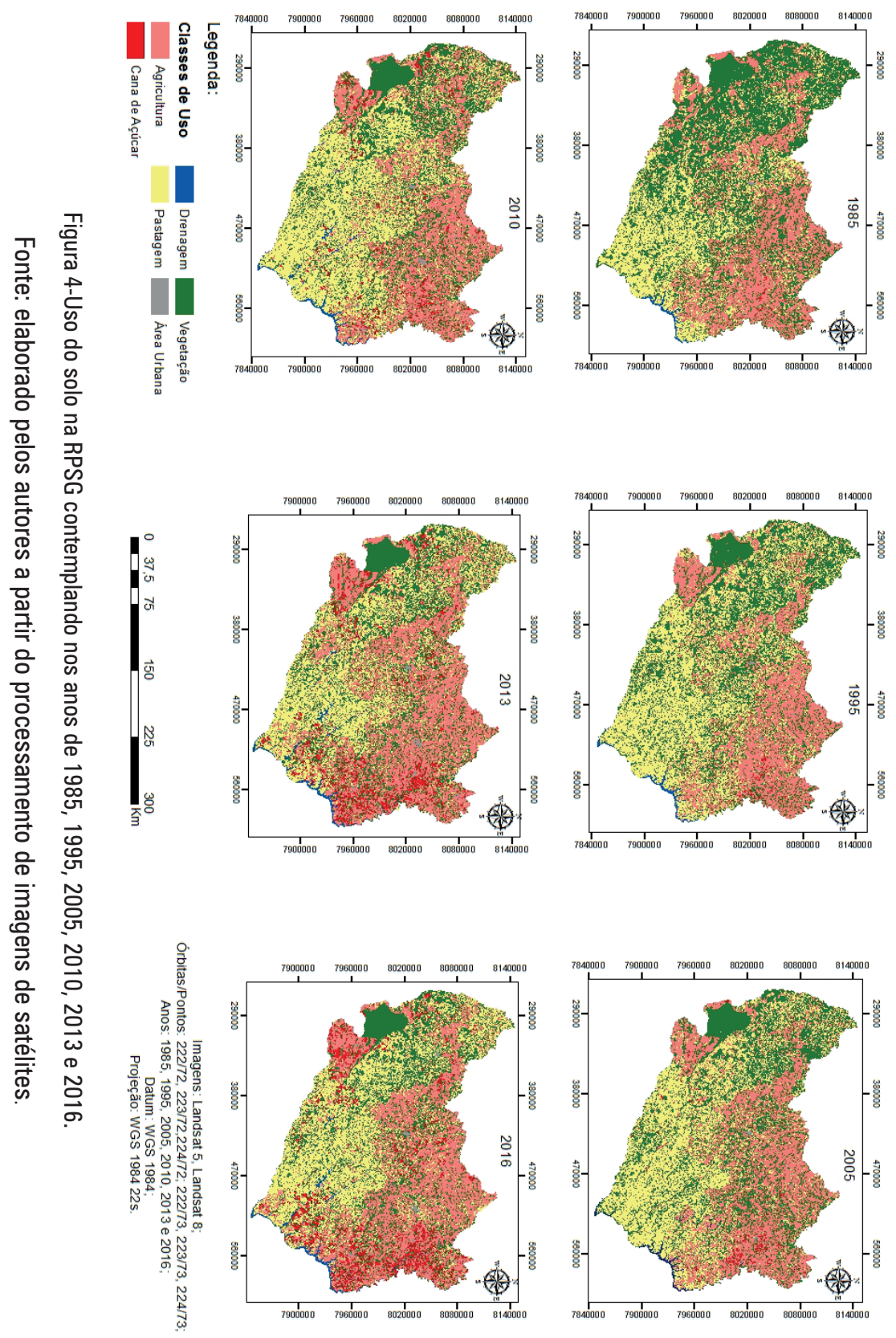




\begin{tabular}{lrrrrrr}
\hline \multicolumn{1}{c}{ Uso do Solo } & \multicolumn{1}{c}{$\mathbf{1 9 8 5}$} & \multicolumn{1}{c}{1995} & \multicolumn{1}{c}{$\mathbf{2 0 0 5}$} & \multicolumn{1}{c}{$\mathbf{2 0 1 0}$} & \multicolumn{1}{c}{$\mathbf{2 0 1 3}$} & \multicolumn{1}{c}{$\mathbf{2 0 1 6}$} \\
\hline Agricultura & $1.835 .555,15$ & $1.812 .589,49$ & $2.040 .221,72$ & $1.951 .659,00$ & $2.460 .597,17$ & $2.180 .902,54$ \\
Pastagem & $1.664 .491,28$ & $2.261 .631,78$ & $2.045 .402,40$ & $2.260 .286,49$ & $1.659 .564,66$ & $1.853 .001,97$ \\
Vegetação & $2.594 .061,05$ & $1.997 .667,04$ & $1.954 .333,47$ & $1.713 .394,99$ & $1.606 .437,98$ & $1.574 .223,31$ \\
Cana de Açúcar & $7.677,88$ & $25.356,45$ & $50.838,37$ & $143.729,53$ & $340.832,82$ & $452.427,80$ \\
Água & $32.309,10$ & $35.745,82$ & $41.790,27$ & $59.325,11$ & $59.484,53$ & $61.510,44$ \\
Área Urbana & $8.053,95$ & $9.157,83$ & $9.562,19$ & $13.753,30$ & $15.231,25$ & $20.082,34$ \\
\hline \multicolumn{1}{c}{ Total } & $\mathbf{6 . 1 4 2 . 1 4 8 , 4 1}$ & $\mathbf{6 . 1 4 2 . 1 4 8 , 4 1}$ & $\mathbf{6 . 1 4 2 . 1 4 8 , 4 1}$ & $\mathbf{6 . 1 4 2 . 1 4 8 , 4 1}$ & $\mathbf{6 . 1 4 2 . 1 4 8 , 4 1}$ & $\mathbf{6 . 1 4 2 . 1 4 8 , 4 1}$ \\
\hline
\end{tabular}

Tabela 1-Uso do Solo no Sudoeste Goiano de 1985 a 2016

Fonte: elaborado pelos autores a partir dos mapas de uso do solo.

O Sudoeste Goiano se tornou uma das principais regiões agrícolas do País, baseada na formação de grandes complexos agroindustriais que são cadeias completas da produção agrícola e que contemplam desde a produção da matéria-prima, passando pelo processamento e logística, até a chegada ao mercado consumidor. É possível, então, compreender que elas se inserem no contexto do avanço da fronteira agrícola ligado à modernização da agricultura, ocupando áreas de maior valor agregado e que demandam grandes investimentos em tecnologia (Kageyama et al., 1996; Silva, J., 1983).

Essa dinâmica pode ser observada diante das sucessões temporais do uso do solo, em que a agricultura e as pastagens mantiveram predomínio juntamente com o crescimento sucroenergético. Nesse sentido, as políticas públicas do setor ficaram definitivamente marcadas na região. O PROÁLCOOL, conforme afirmado por Alves e Szmrecsányi (2008), apresentou-se em três fases 1975/1979, 1979/1985 e 1990/2000, marcadas pela ampliação da produção canavieira e redução da produção de açúcar; e pela criação de usinas autônomas e as crises de abastecimento que levaram ao fim do programa. Bem mais tarde, após grande período de relativa estagnação, como é conhecido, surgiu o Plano Nacional de Agroenergia, que, entre os seus objetivos, destaca-se a mudança da matriz energética que contribui com a ampliação da produção agroenergética brasileira.

Com base nos dados gerados (Figura 4, Tabela 1), é possível afirmar que o setor canavieiro se encontra em expansão desde os primeiros 
períodos analisados, pois não houve registro de redução em área plantada na região. A concentração da produção canavieira iniciou-se antes do período de vigência do PROÁLCOOL, a leste, nos municípios de Santa Helena de Goiás e Turvelândia, onde se encontram as primeiras usinas processadoras.

O setor apresentou um padrão de concentração compatível com o modelo de expansão radial, irradiado do leste regional para oeste. Assim, a expansão seguiu os eixos leste/sul e também a oeste da RPSG (Figura 5). O seu rápido avanço, registrado a partir da implantação do Plano Nacional de Agroenergia, caracterizou a cultura canavieira como um dos principais agentes indutores da substituição de áreas de cultivos comerciais, sobretudo, a produção de grãos e de áreas de vegetação nativa, interferindo de maneira direta e indireta no Cerrado regional.

Dado esse intenso crescimento, Abdala e Ribeiro (2011) demonstraram que o setor avançou sobre outros complexos agroindustriais em Goiás, criando um ambiente de competição produtiva entre a cana, grãos, pecuária e áreas com remanescentes de Cerrado.

\section{A cana-de-açúcar e a dinâmica das mudanças de usos dos solos}

As mudanças de uso do solo fazem parte de um conjunto de alterações relacionadas com a sucessão temporal das classes poligonais das bases físicas e antrópicas da natureza. Essas mudanças representam transições que estão relacionadas com os níveis tecnológicos, onde as práticas de menor ou nenhum padrão de tecnologia, como as áreas de pastagens e de vegetação nativa, sedem lugar para as de maior emprego de técnicas, como a agricultura comercial, incluindo o setor sucroenergético. 


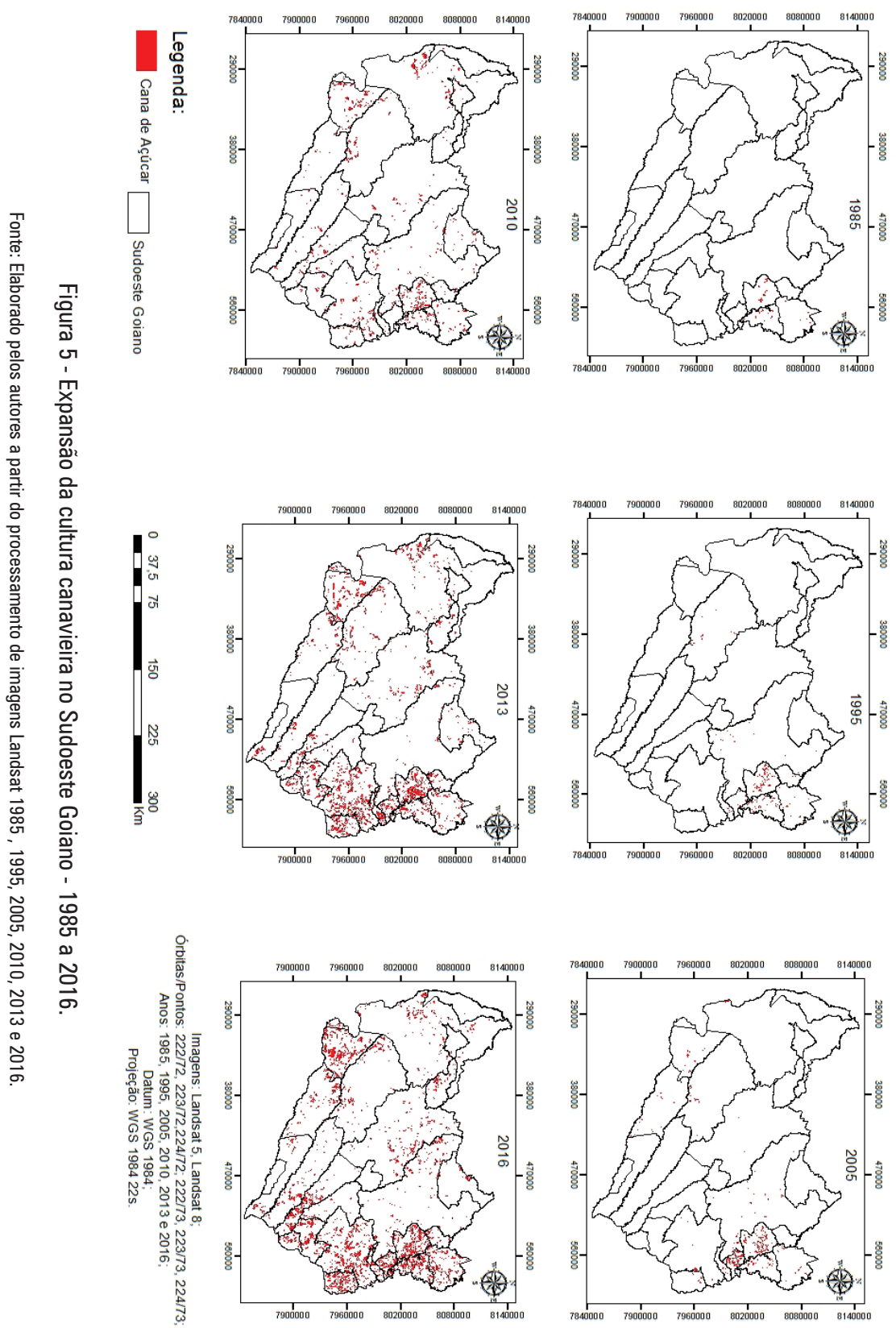


O processo de mudanças de uso do solo atinge, de forma mais intensificada, a área contida num raio de $40 \mathrm{~km}$ das usinas. Essa distância viabiliza a logística do transporte da matéria-prima até as unidades processadoras em tempo hábil (até 72h). Nessas áreas é que a expansão canavieira se torna mais conflitante em relação à disputa por terras com as outras categorias de uso do solo, inclusive a vegetação nativa. Assim, a análise multitemporal das substituições diretas de usos pela cana-deaçúcar corroborou a preferência pelas melhores terras (Figura 6).

A expansão da cana-de-açúcar mostrou que o seu desenvolvimento na RPSG ocorreu sobre áreas agrícolas já consolidadas a leste, deslocando-se para áreas de pastagens a oeste. Esse processo relaciona-se com uma seletividade edáfica que o setor sucroenergético busca, com melhores condições produtivas, que são encontradas nos Latossolos Vermelhos e Latossolos Vermelhos-Amarelos, devido a sua melhor aptidão agrícola (Trindade, 2015).

A inclusão dos biocombustíveis ao PNA criou o discurso oficial de que a cana-de-açúcar iria avançar sobre as áreas de pastagens, principalmente as degradadas, preservando as áreas produtoras de alimentos e as remanescentes de Cerrado (Sauer; Pietrafesa, 2012). Estudos detalhados sobre essa dinâmica, realizados por Castro et al. (2010), mostraram que a conversão das áreas de agricultura e pastagens em áreas de cana-de-açúcar estão inseridas num contexto de competição que inclui os remanescentes de vegetação e os melhores solos. O discurso estruturado sobre o avanço da cana-de-açúcar, sobre as áreas de pastagens degradadas, demonstrou-se conflitante por ocorrer uma verdadeira disputa entre os solos agricultáveis, independentemente do seu uso e ocupação. 

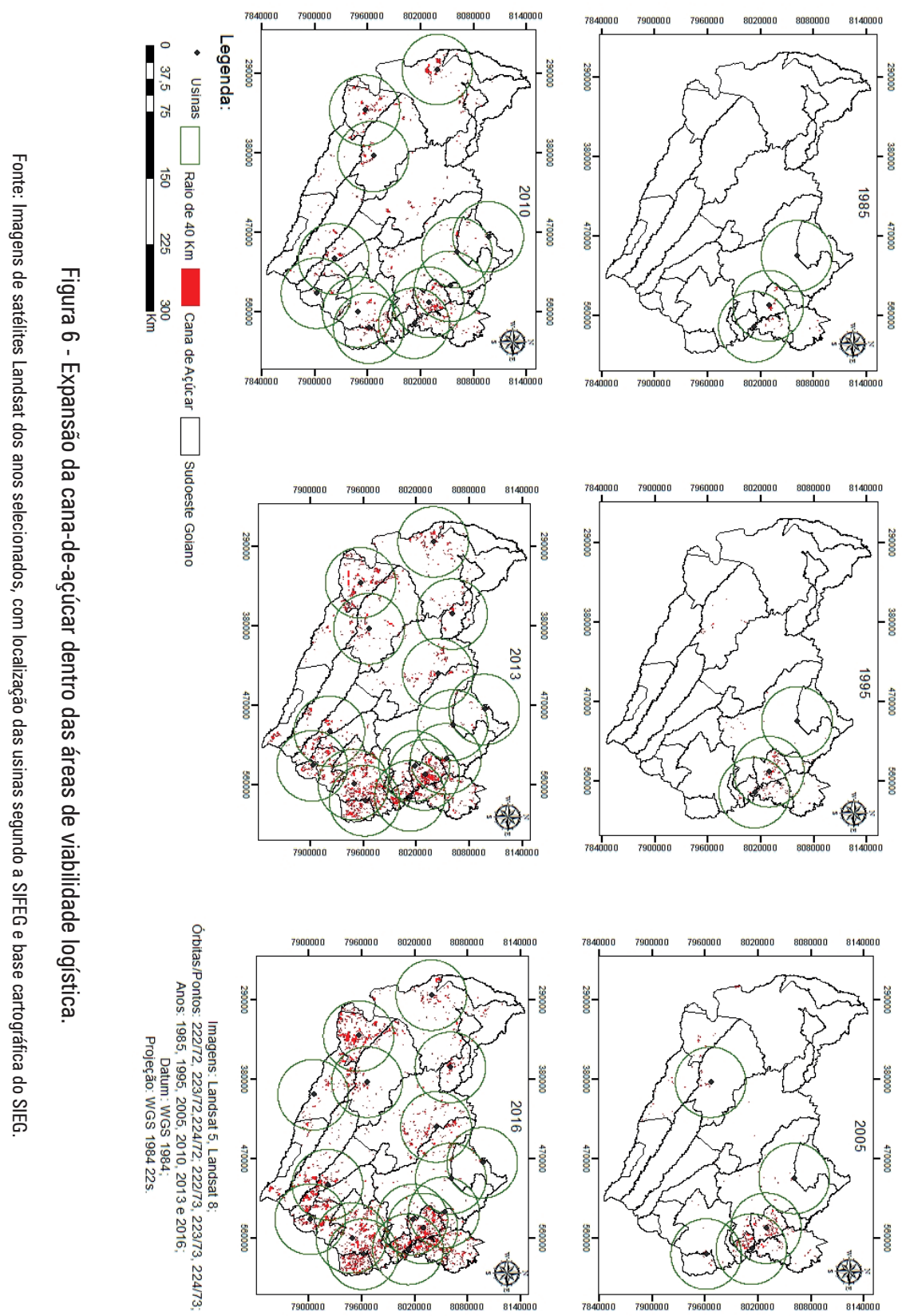
A Figura 7 mostra as mudanças induzidas diretamente pela canade-açúcar, dentro do período analisado. Observe-se que o avanço da cana vem alterando o padrão agrícola e natural do Sudoeste Goiano.

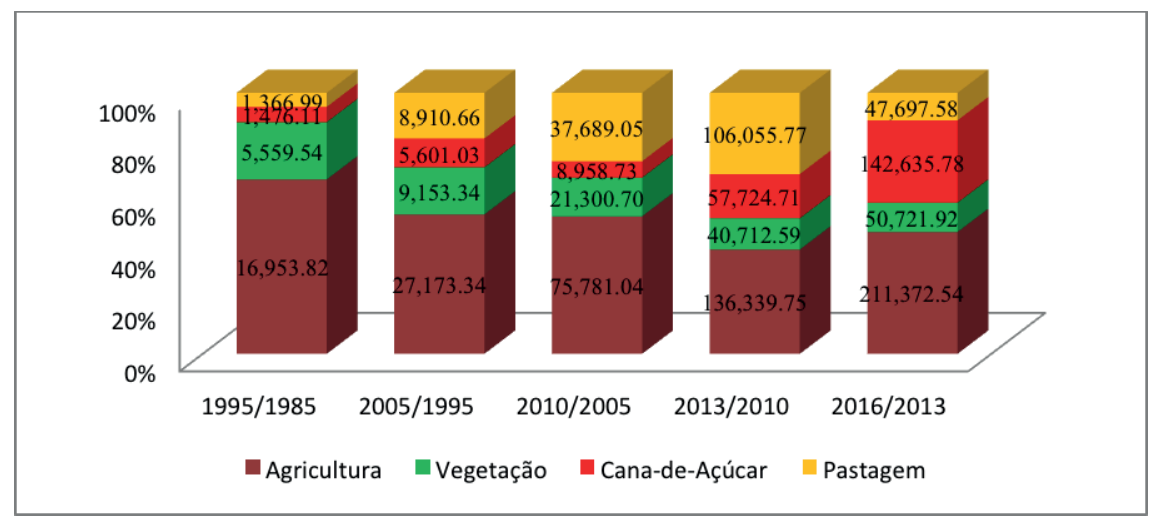

Figura 7 - Efeito de substituição pela cana-de-açúcar no Sudoeste Goiano (1985 a 2016).

Fonte: Mapas de uso do solo dos anos selecionados.

A substituição direta da cana-de-açúcar no período de 1995/1985 mostrou que o seu avanço ocorreu primordialmente sobre as áreas agrícolas (16.953,82 ha), seguidas pela substituição das áreas de vegetação (5.559,54 ha). Também se identificou o avanço da cana para as suas próprias áreas (1.476,11 ha), fato que pode ser explicado pela manutenção dos canaviais já instalados; e, em menor proporção, observa-se o avanço sobre as áreas de pastagens (1.366,99 ha).

O período de 2005/1995 manteve o mesmo padrão anterior, sendo que o avanço da cana-de-açúcar sobre as áreas de agricultura correspondeu a 27.173,34 ha e sobre as de Cerrado a 9.153,34 ha. A expansão prosseguiu sobre as áreas de pastagens (8.910,66 ha) e as áreas de ampliação dos canaviais já existentes (5.601,03 ha).

É importante observar que a substituição direta da cana-de-açúcar associada às mudanças de usos dos solos nos dois primeiros decênios analisados correspondem ao modelo político de expansão durante a acessão direta e transitória do PROÁLCOOL. Esse modelo priorizou as áreas agrícolas e de vegetação nativa. Segundo estudos realizados por Vaz, Steckelberg, Pietrafesa (2015), o cenário da expansão canavieira vem 
substituindo essas áreas de produção de alimentos e de preservação, tendo como um agente intermediário as pastagens.

A expansão da cana-de-açúcar no período 2010/2005, já de atuação do Plano Nacional de Agroenergia (PNA), mostrou mudanças nesse padrão de substituição, visto que o seu avanço ocorreu sobre as áreas agrícolas (75.781,04 ha), seguidas pelas áreas de pecuária ou de pastagens (37.689,05 ha), de vegetação nativa (21.300,70 ha) e por fim de ampliação dos canaviais formados (8.958,73 ha).

Conforme salientado por Barbalho, A. Silva e Castro (2013), apesar dos esforços do PNA, em priorizar áreas de passagens degradadas, a cana continua a avançar sobre as áreas de agricultura, comprovando que o setor se encontra em disputa por terras, no caso com as áreas de produção de grãos, entrando em contradição com as políticas públicas de agroenergia.

As mudanças do uso do solo em relação à expansão da cana-deaçúcar, no período 2013/2010, ocorreram mais uma vez, principalmente sobre as áreas agrícolas $(136.339,75)$, seguidas pelas áreas de pastagens (106.055,77 ha), de reforma de cana-de-açúcar (57.724,71 ha) e de vegetação natural (40.712,59 ha). Tais mudanças corroboram o exposto por Castro et al. (2010) e A. Silva e Miziara (2011), quanto ao avanço canavieiro sobre áreas de grãos e, secundariamente, de pastagens, em divergência com o discurso oficial. Nesse período, ainda é interessante ressaltar a permanência das áreas que já abrigavam a cana-de-açúcar da fase do PROÁLCOOL, reduzindo o seu avanço para as áreas de Cerrado e registrando, pela primeira vez, uma diminuição do desmatamento das áreas naturais.

Os dois últimos quinquênios mostraram que o padrão de expansão canavieira na RPSG sofreu influência exclusiva da nova política setorial, o PNA, substituindo grandes áreas de produção de grãos, em disputa por terras e em conflito com a biodiversidade, portanto, em desacordo com o previsto. Além disso, as terras têm aptidão regular para a cana, segundo o Zoneamento Agroecológico da Cana (Manzatto et al., 2009).

O último período analisado, 2016/2013, mostrou que a canade-açúcar continuou o avanço sobre as áreas agrícolas (211.372,54 ha), seguido pela ampliação das áreas já com cana-de-açúcar (142.635,78 ha), pelas áreas de vegetação (50.721,92 ha) e, por fim, de pastagens (47.697,58 ha). Esse substancial avanço sobre as áreas agrícolas e a ampliação das lavouras canavieiras já existentes enfatizam o fenômeno de seletividade de instalação do complexo agroindustrial sucroenergético, uma vez que 
o setor se insere em um elevado padrão tecnológico de produção agrícola (Silva, A.; Miziara, 2011). Por outro lado, a permanência do avanço sobre as demais classes de uso do solo mostra os critérios de preço da terra, que também podem estar associados à escassez dos solos com aptidão mais elevada. Assim, se os custos das áreas eram menores devido a já terem sido preparadas e manejadas para a soja, eles aumentam com a adaptação do solo para a cana.

Dessa forma, por todo período (exceto o primeiro) domina a conversão de uso do solo por substituição direta por cana-de-açúcar em áreas agrícolas, inclusive sob a vigência do PNA. Este acaba por repetir as antigas práticas do setor, dificultando o avanço dentro de uma nova realidade conservacionista e reabilitadora de áreas degradadas. Também são evidentes as mudanças indiretas de uso do solo, ou seja, repete-se o mesmo modelo que antecedeu a cana-de-açúcar e que integra o remanejamento das outras classes de usos que influenciam os novos avanços sucroenergéticos como um todo. A Figura 8 mostra essa dinâmica das mudanças indiretas proporcionadas pela cana-de-açúcar.

As áreas de pastagens foram as classes de uso que mais avançaram sobre o Cerrado nativo no período, correlacionadas ao intenso avanço agrícola sobre as áreas de pastagens não ocupadas pela cana e de vegetação remanescente. Isso porque o crescente aumento da cana-de-açúcar deu-se predominantemente em substituição às áreas de grãos, em que há menor investimento para produção porque são os melhores solos. Ela também substituiu as áreas de pastagens e de vegetação com condições edáficas para a produção da matéria-prima para o etanol/açúcar, representando a influência canavieira na dinâmica das outras classes de usos no Sudoeste Goiano.

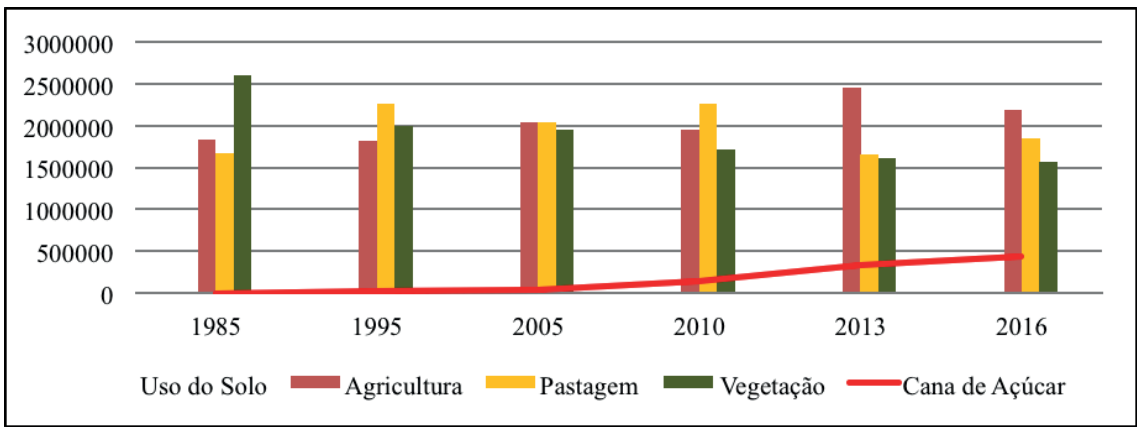

Figura 8-Dinâmica das mudanças de usos do solo no Sudoeste Goiano (1985 a 2016). 
vConclusões

Entre os anos de 1985 e 2016 o avanço sucroenergético na RPSG mostrou importantes mudanças de uso do solo, que corroboram a dinâmica similar à da fronteira agrícola dos anos 70 do século passado. As mudanças se deram, inicialmente, na fase do PROÁLCOOL, com base no modelo de produção em que o etanol e açúcar eram produzidos com menor emprego de tecnologia e sem disputa por terras com outras culturas.

Após essa fase, a expansão sucroalcooleira recente mudou de padrão, dentro do seu âmbito de influência direta num raio de $40 \mathrm{~km}$ das usinas, onde a cana promoveu a competição por terras relacionadas aos complexos agroindustriais já consolidados, principalmente o de grãos (agricultura) e o da carne (pastagens). Nesse sentido, a cana-de-açúcar ocupou primordialmente áreas de agricultura já formadas, cujo padrão de avanço caracterizava-se por preferência pelas regiões de maior potencial de uso e ocupadas por grãos. A análise das mudanças de uso indiretas sugere que as pastagens cederam lugar aos grãos de maior rentabilidade, porém sobre solos que requerem mais práticas e conservacionistas e, nessa perspectiva, os pastos avançaram sobre as áreas de vegetação nativa, expandindo a fronteira agrícola.

Os resultados desta pesquisa permitiram deduzir que os efeitos da expansão da cana-de-açúcar no Sudoeste Goiano entram em confronto com as diretrizes ambientais do Plano Nacional de Agroenergia. A análise da produção sucroenergética indica impactos na produção de alimentos e na biodiversidade, e é caracterizada pelo seu progresso, principalmente, sobre as áreas agrícolas e as áreas de vegetação nativa.

\section{Agradecimentos}

Agradecemos à CAPES pela bolsa de pesquisa concedida ao primeiro autor; ao CIAMB/UFG, Programa de Pós-graduação em Ciências Ambientais, pelo apoio no desenvolvimento desta pesquisa; ao Laboratório e Geomorfologia, Pedologia e Geografia Física/LABOGEF do Instituto de Estudos Sócio-Ambientais/IESA da Universidade Federal de Goiás/UFG; e à EMBRAPA/Solos pelo apoio técnico. 


\section{Referências}

ABDALA, K. O. ; RIBEIRO, F. L. Análise dos impactos da competição pelo uso do solo no estado de Goiás durante o período 2000 a 2009 provenientes da expansão do complexo sucroalcooleiro. Revista Brasileira de Economia, Rio de Janeiro, v. 65, n. 4, p. 373-400, out/dez. 2011.

ALVES, F.; SZMRECSÁNYI, F. Produção e suas alternativas. In: ALVES, F. et al. Certificação Socioambiental para Agricultura: desafios para o setor sucroalcooleiro. Piracicaba: Edufscar, 2008, p 90-121.

BARBALHO, M. G. S.; SILVA, A. A.; CASTRO, S. S. A expansão da área de cultivo da cana-de-açúcar na região sul do estado de Goiás de 2001 a 2011. Revista Brasileira de Ciências Ambientais, Rio de Janeiro, n. 29, p. 98-110, set. 2013.

CASTRO, S. S. et al. A Expansão da Cana-de-açúcar no Cerrado e no Estado de Goiás: elementos para uma análise espacial do processo. Boletim Goiano de Geografia, Goiânia, v. 30, n. 1, p. 171-191, jan./jun. 2010.

COUTINHO, A. C. Segmentação e classificação de imagens LANDSAT-TM para o mapeamento dos usos da terra na região de Campinas, SP. 1997. 144 f. Dissertação (Mestrado em Ciência), Universidade de São Paulo, São Paulo, 1997.

HOUTART, F. A Agroenergia: solução para o clima ou saída da crise para o capital? Tradução de Francisco Morás. Petrópolis: Vozes, 2010. 324 p.

INSTITUTO BRASILEIRO DE GEOGRAFIA E ESTATÍSTICA (IBGE). Manual Técnico de Uso das Terras. Rio de Janeiro. 2. ed. IBGE: Rio de Janeiro, 2006. 91 p.

KAGEYAMA, A. et al. O novo padrão agrícola brasileiro: do complexo rural aos complexos agroindustriais. In: DELGADO, G. C; GASQUES, J. G; VILLA VERDE, C. M. Agricultura e Políticas Públicas. 2. ed. Brasília: IPEA, 1996. p. 113-224.

LATRUBesse, E. M.; CARVALHO, T. M. Mapa Geomorfológico de Goiás e Distrito Federal. Goiânia: Superintendência de Geologia e Mineração do Estado de Goiás, 2006. 67 p.

LIMA, D. A. L. L.; GARCIA, J. R. A evolução da produção de cana-de-açúcar e o impacto no uso do solo no Estado de Goiás. Estudos Sociedade e Agricultura, Rio de Janeiro, v. 19, p. 374-403, out. 2011.

MACEDO, I.C. Energia da cana-de-açúcar: doze estudos sobre a agroindústria da cana-de-açúcar no Brasil e a sua sustentabilidade. 2. ed. São Paulo: Berlendis \& Vertecchia; ÚNICA, 2005. 235 p.

MANZATTO, et al. Zoneamento agroecológico da cana-de-açúcar: expandir a produção, preservar a vida e garantir o futuro. Rio de Janeiro: EMBRAPA Solos, 2009. $55 \mathrm{p}$.

OLIVEIRA, E. B.; FERREIRA, M. E.; ARAÚJO, F. M. Diagnóstico do uso da terra na região Centro-Oeste de Minas Gerais, Brasil: a renovação da paisagem pela cana-de-açúcar e seus impactos socioambientais. Revista Sociedade \& Natureza, v. 24, n. 3, p. 545-555, set./dez. 2012. 
OLIVEIRA, W.N.; FERREIRA, N.C. Avaliação Multitemporal do Uso e Cobertura do Solo da Bacia Hidrográfica do Ribeirão João Leite Utilizando Imagens Landsat-5. Revista Brasileira de Ciências Ambientais, Rio de Janeiro, v. 1, n. 38, p. 46-62, dez. 2015.

PRADO, L.; MIZIARA, F.; FERREIRA, M. F. Expansão da fronteira agrícola e mudanças no uso do solo na região Sul de Goiás: ação antrópica e características naturais do espaço. Boletim Goiano de Geografia, Goiânia, v. 32, n. 1, p. 151-165, jan./jun. 2012.

RUDORFF, B.F.T.; SUGAWARA, L.M. Mapeamento da Cana-de-Açúcar na Região Centro-Sul Via Imagens de Satélites. Informe Agropecuário, Belo Horizonte, v. 28, n. 241, p. 79-86, nov./dez. 2007.

SANTOS, R. F. Planejamento ambiental: teoria e prática. 1. ed. São Paulo: Oficina de Textos, 2004. 184 p.

SAUER, S.; PIETRAFESA, J.P. Cana de açúcar, financiamento, público e produção de alimentos no Cerrado. CAMPO-TERRITÓRIO: revista de geografia agrária, Uberlândia, v. 7, n. 14, p. 1-29, ago. 2012.

SILVA, J. F. G. Os resultados da modernização agrícola dos anos 70. Estudos Econômicos. Instituto de Pesquisas Econômicas, São Paulo, v. 13, n. 3, p. 537560, 1983.

SILVA, A. A.; CASTRO, S. S. Dinâmica de uso da terra e expansão da cana-deaçúcar entre os anos de 2004 e 2010, na microrregião de Quirinópolis, Goiás. In: PIETRAFESA, J. P.; SILVA, S. D. de (Org.). Transformações no Cerrado: progresso, consumo e natureza. Goiânia: Ed. PUC Goiás, 2011. p. 155-170.

SILVA, A. A.; MIZIARA, F. O Avanço do Setor Sucroalcooleiro e a Expansão da Fronteira Agrícola em Goiás. Pesq. Agropec. Trop., Goiânia, v. 41, n. 3, p. 399407, jul./set. 2011.

SILVA, A. A.; SANTANA, G. R. S. de; BORGES, V. M. dos S.; CASTRO, S. S. de. Alterações físicas, químicas e morfológicas em um Latossolo VermelhoAmarelo sob cultivo de cana-de-açúcar na microrregião de Quirinópolis, Goiás. In: CONGRESSO BRASILEIRO DE CIÊNCIA DO SOLO, 33., 2011, UberlândiaMG. Anais... Uberlândia: SBCS, 2011. p. 1587-1592.

TRINDADE, S. P. Aptidão agrícola, mudanças de usos dos solos, conflitos e impactos diretos e indiretos da expansão da cana-de-açúcar na região Sudoeste goiano. 2015. 187 f. Tese (Doutorado em Ciências Ambientais)-Doutorado Interdisciplinar, Universidade Federal de Goiás, Goiânia, 2015.

VAZ, M.S; STECKELBERG, T.B; PIETRAFESA, J.P. Papel da cana na matriz energética brasileira. Fronteiras: Journal of Social, Technological and Environmental Science, Anápolis, v. 4, n. 2, p. 215-229, jul./dez. 2015.

Silas Pereira Trindade - Possui graduação em Geografia pela Universidade Federal de Uberlândia (licenciatura e bacharelado), especialização em Gestão Ambiental pela Faculdade Católica de Uberlândia, mestrado em Geografia pela Universidade Federal de Goiás e doutorado em Ciências Ambientais pela Universidade Federal de Goiás. É docente efetivo da Universidade Estadual de Goiás. https://orcid.org/0000-0001-6680-2661 
Karla Maria Silva de Faria - Possui graduação em Geografia pela Universidade Federal de Goiás, mestrado e doutorado em Geografia pela mesma universidade. Atualmente é docente efetiva da Universidade Federal de Goiás, vinculada ao Programa de Pós Graduação em Ciências Ambientais (CIAMB) e ao Programa de Pós Graduação em Geografia (PPGE0), ambos da UFG. https://orcid.org/0000-0001-9381-932X

Selma Simões de Castro - Graduada e licenciada em Geografia pela Universidade de São Paulo, mestre em Geografia Física e doutora em Ciências / Geografia Física pela mesma universidade. Possui pós-doutorado em Ciência do Solo no INRA-Rennes (França). https://orcid.org/0000-0002-5401-5852

\section{Contribuições dos autores}

Todos os autores contribuíram conjuntamente para o desenvolvimento da pesquisa. O autor Silas Pereira Trindade foi responsável pelo desenvolvimento teórico-conceitual e pela aquisição e processamento de dados e análise; à segunda autora, Karla Maria Silva de Faria, couberam também o desenvolvimento teórico-conceitual e a análise de dados; e a terceira autora, Selma Simões de Castro, foi responsável pela orientação da pesquisa e pela atividade de contribuir com as discussões científicas e intelectuais da interpretação dos dados e revisão do texto apresentado, mapas e gráficos.

Recebido para publicação em 02 de julho de 2018 Aceito para publicação em 29 de agosto de 2018 